\title{
Qualidade pós-colheita de colmos de cana armazenados e seus reflexos na produção de cachaça
}

\author{
Post-harvest quality of stored sugarcane stalks and their reflection \\ on the production of cane spirit
}

\author{
José Humberto de Oliveira Filho ${ }^{1 *}$, Aline Marques Bortoletto', André Ricardo Alcarde ${ }^{1}$ \\ 1 Universidade de São Paulo (USP), Departamento de Agroindústria, Alimentos e Nutrição, Piracicaba, São Paulo/SP - Brasil \\ ${ }^{*}$ Corresponding Author \\ José Humberto de Oliveira Filho, Universidade de São Paulo (USP), Departamento de Agroindústria, Alimentos e Nutrição, Avenida Pádua Dias, 11, \\ CEP: 13418-900, Piracicaba/SP - Brasil, e-mail: josehumberto@iftm.edu.br
}

Cite as: Post-harvest quality of stored sugarcane stalks and their reflection on the production of cane spirit. Braz. J. Food Technol., v. 19, e2015069, 2016.

Received: Set. 18, 2015; Accepted: Jun. 07, 2016

\section{Resumo}

Esta pesquisa teve como objetivos avaliar as características tecnológicas e microbiológicas do caldo de cana colhida e armazenada, assim como seus reflexos na condução dos processos fermentativos e formação dos compostos secundários e contaminantes da cachaça. Depois da colheita da cana-de-açúcar, os colmos foram armazenados à temperatura ambiente $\left(20-32{ }^{\circ} \mathrm{C}\right)$ por períodos de $0,24,48,72$ e 96 horas, sendo o mosto preparado logo após a extração do caldo. As fermentações foram conduzidas em processo de batelada, por cinco ciclos fermentativos, com destilação dos vinhos em alambique de cobre. Foram analisadas as características tecnológicas e microbiológicas do caldo e do processo fermentativo. O armazenamento dos colmos de cana causou significantes perdas na qualidade tecnológica do caldo, influenciando negativamente o processo fermentativo, com decréscimo na viabilidade de células e brotos de leveduras. A utilização de matéria-prima armazenada por períodos superiores a 48 horas contribuiu para a redução do pH e aumento da acidez total e açúcares redutores residuais dos vinhos, refletindo em menor produção de álcool. Os níveis de acidez volátil, acetato de etila, acetaldeído, cobre, metanol e carbamato de etila das cachaças ficaram dentro do estabelecido pela Legislação Brasileira, enquanto o conteúdo de álcoois superiores e furfural apresentaram-se elevados nos destilados de cana colhida e armazenada.

Palavras-chave: Matéria-prima; Armazenamento; Processos fermentativos; Composição química.

\section{Summary}

This research aimed to evaluate the technological and microbiological characteristics of the juice produced from harvested and stored sugarcane, and the reflections on the fermentative processes and formation of secondary compounds and contaminants in the production of cane spirit. After harvesting, the sugarcane stalks were stored at environmental temperature $\left(20-32{ }^{\circ} \mathrm{C}\right)$ for $0,24,48,72$, and 96 hours, the must being prepared soon after juice extraction. The fermentations were carried out using a batch process with five fermentative cycles, distilling the wine in a copper still. The technological and microbiological characteristics of the juice and the fermentation process were analysed. Storage of the cane stalks caused significant losses in the technological quality of the juice, negatively influencing the fermentative process, and decreasing the viability of the yeast cells and shoots. The use of raw material stored for periods longer than 48 hours contributed to a reduction in $\mathrm{pH}$, increase in total acidity and increase in residual reducing sugars in the wines, reflecting in reduced alcohol production. The levels of volatile acidity, ethyl acetate, acetaldehyde, copper, methanol and ethyl carbamate in the cane spirits were within the limits established by Brazilian law, whilst the higher alcohols and furfural contents were high in the distillates produced from harvested and stored sugarcane.

Keywords: Raw material; Storage; Fermentative process; Chemical composition. 


\section{Introdução}

A cachaça é a denominação típica e exclusiva da aguardente de cana produzida no Brasil, com graduação alcoólica de $38 \%$ a $48 \%$ em volume, a $20{ }^{\circ} \mathrm{C}$, obtida pela destilação do mosto fermentado de caldo de cana-de-açúcar, podendo ser adicionada de até $6 \mathrm{~g} \cdot \mathrm{L}^{-1}$ de açúcares (BRASIL, 2005a).

A cana-de-açúcar (Saccharum officinarum) é a principal matéria-prima utilizada para a produção deste destilado. A ocorrência de fatores limitantes ao desenvolvimento da planta e à manutenção do seu estado fisiológico pós-colheita podem refletir em alterações na sua qualidade, impactando o processamento industrial (GARCIA et al., 2010; WATT; CRAMER, 2009).

O armazenamento da cana é um dos principais fatores que determinam as perdas de qualidade da matéria-prima. Estudos têm demonstrado que o intervalo entre colheita e processamento da cana é o principal responsável pelas taxas de perda de sacarose, decorrentes dos processos de inversão e respiração, assim como da formação de ácidos orgânicos e dextrana (MAO et al., 2006; BHATIA et al., 2009).

Na cana-de-açúcar colhida e armazenada, as reações de inversão tornam-se evidentes, devido ao gradual aumento de açúcares redutores, processo catalisado inicialmente por invertases endógenas, e agravado pela ação de invertases de origem microbiana (SOLOMON et al., 2006).

As reações bioquímicas que ocorrem nas fermentações alcoólicas estão envolvidas com a síntese de diversos compostos químicos, dentre eles, álcoois superiores, ésteres, aldeídos e ácidos orgânicos, que são responsáveis pelo aroma e sabor típicos da cachaça, desempenhando um importante papel na formação do perfil sensorial do destilado (ALCARDE et al., 2012a).

Fatores limitantes ao desenvolvimento do processo fermentativo podem comprometer a atividade das leveduras, estimulando o crescimento de micro-organismos contaminantes e a produção de produtos intermediários, afetando a síntese de etanol e de compostos secundários (NOVA et al., 2009; SKINNER; LEATHERS, 2004).

A qualidade química do caldo e a introdução de diferentes linhagens de microrganismos no processo podem ocasionar transtornos operacionais, comprometendo a condução das fermentações e a composição química da cachaça. Assim, o presente estudo teve como objetivos avaliar os efeitos da utilização do caldo da cana armazenada sobre o processo fermentativo e na formação dos compostos secundários e contaminantes da cachaça.

\section{Parte experimental}

O experimento foi conduzido durante a safra 2014/2015 no Instituto Federal de Educação, Ciência e Tecnologia do Triângulo Mineiro (IFTM), campus Uberaba, utilizando-se cana-de-açúcar plantada em área de quarto corte da variedade SP14-7006, colhida manualmente, sem queima da palha e despontada.

Depois da colheita da cana-de-açúcar, quarenta colmos de cana (por tratamento) foram armazenados por períodos de 0, 24, 48, 72 e 96 horas, para cada ciclo fermentativo, em local protegido de chuvas e raios solares, à temperatura atmosférica mínima de $20^{\circ} \mathrm{C}$ e máxima de $32{ }^{\circ} \mathrm{C}$, e umidade relativa média de $25,7 \%$ e $57,6 \%$, respectivamente.

O caldo foi extraído em moenda convencional, marca VM, mod. 91/2 × 14, em intervalos de 0, 24, 48, 72 e 96 horas para cada ciclo fermentativo, sendo posteriormente filtrado e destinado à preparação do mosto (AMORIM, 2005).

O microrganismo utilizado para o desenvolvimento do processo fermentativo foi o fermento comercial prensado (marca Itaiquara), constituído por $30 \mathrm{~g} . \mathrm{L}^{-1}$ de células de Saccharomyces cerevisiae ( $10^{7}$ UFC. $\left.\mathrm{mL}^{-1}\right)$, com viabilidade celular média de 97,8\%. As fermentações foram conduzidas em processo de batelada com recuperação do fermento por decantação, utilizando-se dornas de aço inoxidável de fundo cônico (capacidade total de 22 L), durante cinco ciclos fermentativos com duração aproximada de 24 a 30 horas.

Os tratamentos consistiram de cinco diferentes mostos, obtidos de colmos de cana colhidos e armazenados por períodos de 0, 24, 48, 72 e 96 horas. Cada tratamento recebeu $14 \mathrm{~L}$ de mosto a $16{ }^{\circ} \mathrm{Brix}$, divididos em duas alimentações (7,0 L na primeira alimentação e 7,0 L após intervalo de $60 \mathrm{~min})$.

Depois da conclusão do processo fermentativo, os vinhos provenientes do $1^{\circ}, 3^{\circ}$ e $5^{\circ}$ ciclos fermentativos foram destilados em alambique simples, com caldeira, capitel, alonga e condensador de cobre. O alambique possui sistema de aquecimento a gás e caldeira com capacidade útil de $13 \mathrm{~L}$ de vinho. Foram coletados aproximadamente $2 \mathrm{~L}$ da fração coração do destilado com graduação alcoólica de $40 \%$ V. $v^{-1}$.

Foram determinados Brix (sólidos solúveis totais - SST), Pol (sacarose aparente) e a Pureza Aparente do caldo segundo Consecana (2006). Os valores de $\mathrm{pH}$ do caldo e vinho foram quantificados por leitura direta em pHmetro digital Tekna T-1000, com temperatura corrigida para $25^{\circ} \mathrm{C}$. Os açúcares redutores (AR) e os açúcares redutores totais (ART) do caldo foram determinados pelo método titulométrico de Lane e Eynon (1934) que reduz o cobre do reagente Fehling a óxido de cobre, proporcionando ao meio de reação a formação de um precipitado vermelho-tijolo. A acidez total titulável (ATT) do caldo e do vinho expressa em $\mathrm{gH}_{2} \mathrm{SO} . \mathrm{dm}^{-3}$ foi determinada conforme descrito em Copersucar (2001). Os níveis de álcool nos vinhos foram quantificados em densímetro digital DMA 4500/Anton Paar (SILVA et al., 2003), enquanto os açúcares redutores 
residuais totais (ARRT) foram determinados pelo método de Lane e Eynon (1934).

No início do processo fermentativo (30 min após inoculação), foram analisadas as viabilidades de células e brotos de leveduras, com contagens em Câmara de Neubauer (SILVA et al., 2003).

Foram analisadas também as concentrações de bactérias láticas (MRS Agar - Man, Rogosa e Sharp) do caldo de cana, enquanto no fermento reciclado foram determinadas as populações de leveduras totais (WLN - Wallerstein Laboratories Nutrient Agar), leveduras não Saccharomyces (WLD - WLN + actidione - adição de actidione na forma de solução, ao meio WLN, para uma concentração final de $5 \mathrm{ppm}$ ), bactérias láticas (MRS Agar - Man, Rogosa e Sharp) e microrganismos totais (Plate Count Agar), segundo Ceccato-Antonini (2010).

Por cromatografia em fase gasosa com detector de ionização de chama (GC-FID), foram quantificados aldeído acético, acetato de etila, furfural, álcoois superiores (álcool propílico, isobutanol, álcool isoamílico), ácido acético e metanol. As análises foram realizadas em cromatógrafo a gás Shimadzu modelo QP-2010 PLUS, com coluna Stabilwax-DA (Crossbond Carbowax polietilenoglicol esterificado, $30 \mathrm{~m} \times 0,18 \mathrm{~mm} \times 0,18 \mu \mathrm{m})$ e detector de ionização de chama (FID). As temperaturas do detector e do injetor foram fixadas em $250^{\circ} \mathrm{C} \mathrm{em}$ modo de injeção automática, com divisão de fluxo (split) de 1:25 com um volume de injeção de 1,0 $\mu \mathrm{L}$ da amostra. O fluxo do gás de arraste na coluna $\left(\mathrm{H}_{2}\right)$ foi de $1,5 \mathrm{~mL} \cdot \mathrm{min}^{-1} \mathrm{com}$ fluxo total de $42 \mathrm{~mL} \cdot \mathrm{min}^{-1}$ e pressão de 252,3 KPa. A programação da rampa de temperatura da coluna foi iniciada a $40{ }^{\circ} \mathrm{C}$ (isoterma de $4 \mathrm{~min}$ ), com aumento até $120^{\circ} \mathrm{C}$ a uma taxa de $20^{\circ} \mathrm{C} \cdot \mathrm{min}^{-1}$ (isoterma de $1 \mathrm{~min}$ ) e aumento a $30^{\circ} \mathrm{C} \cdot \mathrm{min}^{-1}$ até $180^{\circ} \mathrm{C}$ (isoterma de $4 \mathrm{~min}$ ) (BORTOLETTO; ALCARDE, 2013).

O conteúdo de carbamato de etila foi determinado em cromatógrafo gasoso (GC) acoplado a um espectrofotômetro de massa (MS), modelo GCMSQP2010 Plus (Shimadzu, Kyoto, Japan), utilizando elétrons de impacto ionizante com energia de 70 eV e uma coluna capilar cromatográfica de fase polar (propileno glicol esterificado, HPFFAP; $50 \mathrm{~m} \times 0.20 \mathrm{~mm} \times 0.33 \mu \mathrm{m}$ de filme de espessura em fase estacionária). As temperaturas de interface do injetor e detector foram de 230 e $220{ }^{\circ} \mathrm{C}$, respectivamente. As temperaturas foram programadas iniciando com $90^{\circ} \mathrm{C}$ por $1 \mathrm{~min}$, aumentando para $150^{\circ} \mathrm{C}$ a uma taxa de $10^{\circ} \mathrm{C} \cdot \mathrm{min}^{-1}$, seguidas por aquecimento até $230^{\circ} \mathrm{C}$ a uma taxa de $30^{\circ} \mathrm{C} \cdot \mathrm{min}^{-1}$ e permanecendo nessa temperatura por $2 \mathrm{~min}$. Um volume de 1,0 $\mu \mathrm{L}$ foi injetado utilizando-se um injetor modelo splitless, em duplicata, sendo hélio utilizado como gás de condução a uma taxa de fluxo de $1.2 \mathrm{~mL}$. $\mathrm{min}^{-1}$. Foi empregado monitoramento do íon $\mathrm{m} / \mathrm{z} 62$ para o carbamato de etila, utilizado como padrão interno
(RECHE et al., 2007; CLEGG; FRANK, 1988). A quantificação foi realizada através de comparações com resultados cromatográficos de amostras com curva analítica obtida, utilizando-se uma solução estoque de carbamato de etila, com concentrações entre 50 e $500 \mu \mathrm{g} \cdot \mathrm{L}^{-1}$ (sem padrão interno) (ALCARDE et al., 2012b).

Os teores de cobre das amostras de cachaça foram determinados em espectrofotômetro de absorção atômica, conforme metodologia oficial para análise de aguardente e cachaça (BRASIL, 2005b).

Os resultados obtidos foram submetidos à análise de variância pelo Teste $F$ e os valores médios comparados pelo teste de Tukey $(P=0,05)$ (BANZATTO; KRONKA, 2006) sendo os dados das contagens de microrganismos transformados em logaritmo $\left(\log _{10}\right)$.

\section{Resultados e discussão}

\subsection{Qualidade do caldo de cana}

Para avaliar os efeitos do armazenamento dos colmos de cana sobre a qualidade do caldo, os parâmetros físico-químicos e microbiológicos foram analisados periodicamente. Com base nos resultados dos parâmetros avaliados (Tabela 1), observa-se que a qualidade do caldo foi significativamente afetada durante $\mathrm{o}$ armazenamento dos colmos.

O armazenamento favorece a desidratação dos colmos de cana, elevando o conteúdo de sólidos solúveis totais. A taxa de inversão da sacarose em açúcares redutores (glicose e frutose) também foi intensificada, levando a uma redução de 2,9\% da sacarose aparente, quando o tempo de armazenamento foi de 96 horas. A porcentagem de ART foi reduzida, enquanto a acidez total aumentou proporcionalmente ao crescimento bacteriano.

Verma et al. (2012) também encontraram reduções na porcentagem de sacarose, e elevação nos níveis de açucares redutores e acidez total em cana-de-açúcar armazenada por períodos de até 120 horas. $\mathrm{O}$ armazenamento pode ter intensificado as alterações fisiológicas nos colmos, contribuindo com o aumento dos processos respiratórios, além de proporcionar condições favoráveis ao crescimento bacteriano, elevando a produção de ácidos orgânicos na matéria-prima. Como consequência dos maiores índices de acidez e da perda de umidade dos colmos armazenados, a atividade de invertases ácidas provavelmente foi favorecida, intensificando os processos de inversão da sacarose.

As reações de inversão e a produção de compostos intermediários, decorrentes da atividade fisiológica da cana e do crescimento microbiano, são fatores que comprometem a manutenção da qualidade do caldo extraído (MAO et al., 2006; SUMAN et al., 2000). 
Qualidade pós-colheita de colmos de cana armazenados e seus reflexos na produção de cachaça

Oliveira Filho, J. H. et al.

Tabela 1. Análises fisíco-químicas e microbiológicas do caldo de cana-de-açúcar colhida e armazenadaa

\begin{tabular}{|c|c|c|c|c|}
\hline Armazenamento & SST & POL & Pureza & AR \\
\hline (h) & ( ${ }^{\circ}$ Brix) & $(\%)$ & $(\%)$ & $(\%)$ \\
\hline 0 & $20,89 D$ & $20,24 \mathrm{~A}$ & $96,87 \mathrm{~A}$ & $0,31 \mathrm{~B}$ \\
\hline 24 & $21,12 \mathrm{CD}$ & $20,39 A$ & $96,58 \mathrm{~A}$ & $0,35 B$ \\
\hline 48 & $21,32 \mathrm{BC}$ & $20,12 \mathrm{~A}$ & $94,39 \mathrm{~B}$ & $0,49 B$ \\
\hline 72 & $21,55 \mathrm{AB}$ & $20,20 \mathrm{~A}$ & $93,76 \mathrm{~B}$ & $0,97 \mathrm{~A}$ \\
\hline 96 & $21,70 \mathrm{~A}$ & $19,65 B$ & $90,61 \mathrm{C}$ & $1,58 \mathrm{~A}$ \\
\hline DMS & $0,29^{\star *}$ & $0,38^{* *}$ & $2,08^{\star *}$ & $0,287^{\star \star *}$ \\
\hline CV $(\%)$ & 1,33 & 1,84 & 2,14 & 37,4 \\
\hline Armazenamento & ART & ATT & $\mathrm{nH}$ & CBAL \\
\hline (h) & $(\%)$ & $\left(\mathrm{gH}_{2} \mathrm{SO}_{4} \cdot \mathrm{dm}^{-3}\right)$ & pn & $\left(10^{2} \mathrm{UFC} \cdot \mathrm{mL}^{-1}\right)$ \\
\hline 0 & $20,25 \mathrm{~A}$ & $0,75 \mathrm{C}$ & $5,30 \mathrm{~A}$ & $3,22 B$ \\
\hline 24 & $20,14 \mathrm{~A}$ & $0,79 B C$ & $5,27 \mathrm{~A}$ & $3,28 \mathrm{~B}$ \\
\hline 48 & $18,77 \mathrm{~B}$ & $0,88 \mathrm{AB}$ & $5,30 \mathrm{~A}$ & $3,40 \mathrm{AB}$ \\
\hline 72 & $18,20 B$ & $0,91 \mathrm{~A}$ & $5,29 A$ & $3,60 \mathrm{~A}$ \\
\hline 96 & $17,46 \mathrm{C}$ & $0,96 \mathrm{~A}$ & $5,27 \mathrm{~A}$ & $3,63 \mathrm{~A}$ \\
\hline DMS & $43,78^{\star \star}$ & $0,102^{\star \star}$ & $0,35^{\mathrm{NS}}$ & $0,27^{\star \star}$ \\
\hline CV $(\%)$ & 0,74 & 11,44 & 1,93 & 7,83 \\
\hline
\end{tabular}

a Médias seguidas de letras iguais na mesma coluna não diferem significativamente pelo teste de Tukey. ${ }^{*} P<0,01$. Ns: não significativo. SST: sólidos solúveis totais; AR: açúcares redutores; ART: açúcares redutores totais; ATT: acidez total titulável; CABL: contagem de bactérias ácido láticas.

\subsection{Avaliações microbiológicas do processo fermentativo}

O monitoramento do processo fermentativo foi realizado através das análises microbiológicas do vinho e do fermento reciclado. Os resultados revelaram um impacto significativo na viabilidade de células e brotos de leveduras em fermentações conduzidas com colmos armazenados. Os efeitos foram mais expressivos para os períodos de 72 e 96 horas de armazenamento, com decréscimo de até 4,3\% e 21,9\% no número de células e brotos viáveis, respectivamente (Figura 1).

Significativa redução na viabilidade de brotos também foi observada, quando se avaliou a reutilização do fermento nos ciclos (Figura 2). As fermentações conduzidas com mosto de cana colhida e armazenada durante até 24 horas permitiram a manutenção de brotos viáveis durante os ciclos, com taxas de crescimento mais elevadas. Para os demais tratamentos, observaram-se reduções significativas, principalmente após o $3^{\circ}$ ciclo, no qual foi registrado um decréscimo de 33\%, em fermentações do caldo de cana armazenada por 96 horas.

A redução da viabilidade pode estar associada a diversos fatores, dentre eles, a disponibilidade de nutrientes e a presença de contaminantes decorrentes da matéria-prima deteriorada. A perda de qualidade da matéria-prima é reconhecidamente um dos principais aspectos responsáveis pela redução da viabilidade de células e brotos de Saccharomyces cerevisiae em fermentações do caldo de cana (GARCIA et al., 2010; RAVANELI et al., 2011).

Os maiores níveis de ácidos orgânicos e a redução de açúcares disponíveis nos colmos de cana armazenados

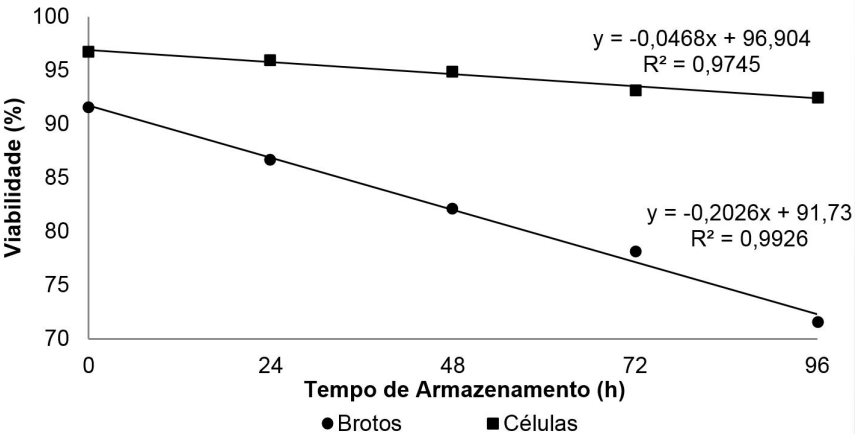

Figura 1. Valores médios para viabilidade de células e brotos de leveduras em fermentações conduzidas com caldo de cana colhida e armazenada.

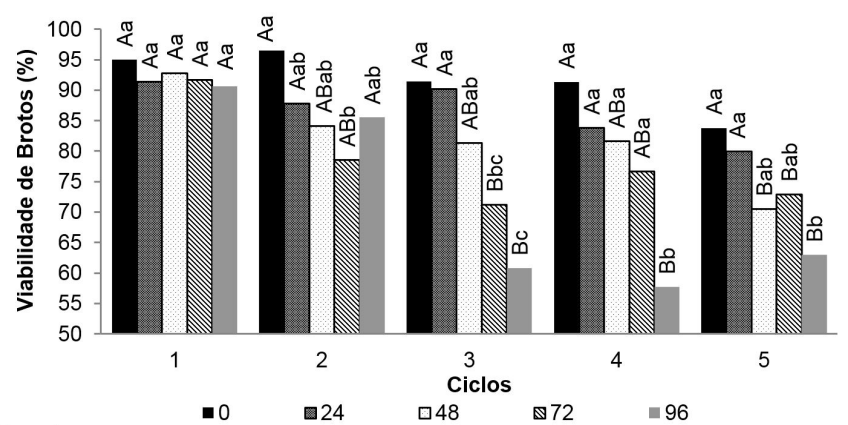

Figura 2. Interação entre tratamentos e ciclos para viabilidade de brotos em fermentações conduzidas com caldo de cana colhida e armazenada. Letras maiúsculas comparam médias entre ciclos com mesmo tratamento. Letras minúsculas comparam médias entre os tratamentos de cada ciclo.

são fatores que comprometem o desempenho das leveduras no processo, implicando em reduções no número de células e brotos viáveis. Considerando-se que as leveduras são 
reutilizadas em ciclos fermentativos posteriores, é de extrema importância a manutenção celular, sendo, portanto, fundamental a utilização de matéria-prima de qualidade, visando criar um ambiente favorável ao seu metabolismo.

A análise microbiológica do fermento demonstra que, a perda de qualidade dos colmos de cana armazenados proporcionou alterações na composição microbiológica do inóculo, aumentando as concentrações de bactérias láticas e leveduras não Saccharomyces, enquanto, as contagens de microrganismos e leveduras totais foram reduzidas. Este comportamento foi mais significativo para o tempo de armazenamento de 96 horas, provavelmente devido às maiores alterações nas características tecnológicas do caldo neste período (Tabela 2).

A biodiversidade de microrganismos (bactérias e leveduras) existentes em fermentações alcoólicas destinadas à produção de cachaça (GOMES et al., 2010; GUERRA et al., 2001) pode ser decorrente da introdução de microrganismos no processo, provenientes do caldo de cana e por ocasião do processamento (BADOTTI et al., 2010).

Embora os níveis de bactérias láticas e leveduras não Saccharomyces no fermento reciclado sejam baixos (10 e $10^{2}$ UFC. $\mathrm{mL}^{-1}$, respectivamente), verificou-se que a qualidade microbiológica e tecnológica dos colmos armazenados são fatores que comprometem o desempenho das leveduras, favorecendo o crescimento de outras linhagens de microrganismos no processo.

\subsection{Características tecnológicas do vinho}

A utilização de colmos de cana armazenados nas fermentações aumentou os níveis de acidez nos vinhos, resultando em baixos valores de $\mathrm{pH}$ (Figura 3).
A produção de ácidos aumentou em maior proporção, nas fermentações conduzidas com colmos armazenados por 72 e 96 horas $\left(R^{2}=0,9754\right)$.

Provavelmente, a menor qualidade tecnológica do caldo associada ao crescimento de bactérias e leveduras não Saccharomyces no fermento reciclado contribuíram com a elevação dos níveis de acidez e redução do pH dos vinhos, comprometendo a manutenção de células e brotos viáveis de leveduras durante as fermentações. As bactérias láticas podem produzir ácido lático e acético, ocasionando inibição na taxa de crescimento específica das leveduras (NARENDRANATH et al., 2001) enquanto, linhagens de leveduras não Saccharomyces, também podem contribuir com a elevação dos níveis de ácido acético no caldo fermentado (DUARTE et al., 2013).

A quantidade de açúcares redutores residuais totais (ARRT) dos vinhos foram maiores a partir do

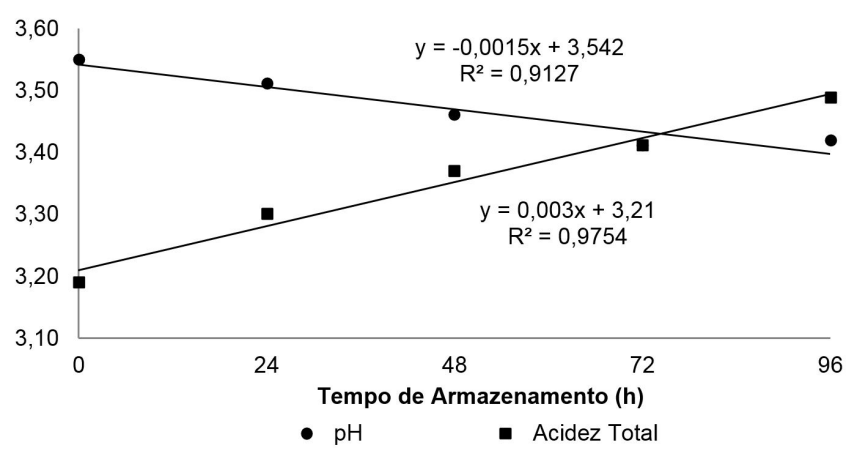

Figura 3. Valores médios de $\mathrm{pH}$ e acidez total $\left(\mathrm{gH}_{2} \mathrm{SO}_{4} \cdot \mathrm{dm}^{-3}\right)$ para mosto fermentado de cana colhida e armazenada.

Tabela 2. Valores médios para as contagens de microrganismos no fermento recicladoa.

\begin{tabular}{|c|c|c|c|c|}
\hline Armazenamento (h) & $\begin{array}{c}\text { Contagem total } \\
\left(10^{7} \mathrm{UFC} \cdot \mathrm{mL}^{-1}\right)\end{array}$ & 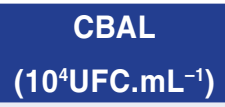 & $\begin{array}{l}\text { Leveduras totais } \\
\left.\text { (107UFC. } \mathrm{mL}^{-1}\right)\end{array}$ & $\begin{array}{c}\text { LNS } \\
\left(10^{2} \text { UFC.mL-1) }\right.\end{array}$ \\
\hline 0 & $8,90 \mathrm{~A}$ & $5,44 \mathrm{~B}$ & $8,94 \mathrm{~A}$ & $3,85 \mathrm{C}$ \\
\hline 24 & $8,87 \mathrm{~A}$ & $5,55 \mathrm{AB}$ & $8,91 \mathrm{~A}$ & $3,94 \mathrm{ABC}$ \\
\hline 48 & $8,89 \mathrm{~A}$ & $5,63 \mathrm{AB}$ & $8,92 \mathrm{~A}$ & $3,92 \mathrm{BC}$ \\
\hline 72 & $8,86 \mathrm{~A}$ & $5,69 A B$ & $8,92 \mathrm{~A}$ & $3,99 A B$ \\
\hline 96 & $8,74 \mathrm{~B}$ & $5,78 \mathrm{~A}$ & $8,74 \mathrm{~B}$ & $4,05 \mathrm{~A}$ \\
\hline DMS & $0,07^{*}$ & $0,33^{*}$ & $0,07^{*}$ & $0,13^{*}$ \\
\hline \multicolumn{5}{|l|}{ Ciclos } \\
\hline 1 & $9,00 \mathrm{~A}$ & $4,69 \mathrm{C}$ & $9,06 \mathrm{~A}$ & $4,32 \mathrm{~A}$ \\
\hline 2 & $8,97 \mathrm{~A}$ & $5,33 \mathrm{~B}$ & $8,98 \mathrm{~B}$ & $4,21 \mathrm{~A}$ \\
\hline 3 & $8,81 \mathrm{~B}$ & $5,98 \mathrm{~A}$ & $8,86 \mathrm{C}$ & $3,77 \mathrm{~B}$ \\
\hline 4 & $8,76 \mathrm{BC}$ & $6,02 \mathrm{~A}$ & $8,80 \mathrm{C}$ & $3,73 \mathrm{~B}$ \\
\hline 5 & $8,73 \mathrm{C}$ & $6,08 \mathrm{~A}$ & $8,73 \mathrm{D}$ & $3,71 \mathrm{~B}$ \\
\hline DMS & $0,072^{*}$ & $0,33^{*}$ & $0,07^{*}$ & $0,13^{*}$ \\
\hline $\mathrm{T} \times \mathrm{C}$ & $1,68^{\mathrm{NS}}$ & $0,15^{\mathrm{NS}}$ & $1,09^{\mathrm{NS}}$ & $0,47^{\mathrm{NS}}$ \\
\hline CV $(\%)$ & 0,78 & 5,78 & 0,76 & 3,08 \\
\hline
\end{tabular}

a Médias seguidas de letras iguais na mesma coluna, para tratamentos, não diferem significativamente pelo teste de Tukey. ${ }^{*} P<0,05$. Ns: não significativo. CBAL: contagens de bactérias ácido láticas; LNS: leveduras não Saccharomyces. 
$5^{\circ}$ ciclo, em fermentações conduzidas com caldo de cana armazenada por 72 e 96 horas (Figura 4). A menor qualidade tecnológica do caldo associada ao crescimento de contaminantes no fermento reciclado são fatores que favorecem o comprometimento das leveduras no processo, reduzindo assim a assimilação dos substratos.

Foi observada também redução de 11,6\% no conteúdo alcoólico dos vinhos em fermentações conduzidas com mosto de cana armazenada por 96 horas (Figura 5), resultado já esperado, pois o armazenamento dos colmos de cana influencia negativamente o desempenho das leveduras durante as fermentações $\left(R^{2}=0,9619\right)$.

\subsection{Componentes secundários da cachaça}

A partir da análise dos compostos secundários e contaminantes da cachaça (Tabela 3), verificou-se que a acidez volátil manteve-se em níveis baixos durante os ciclos para todos os tratamentos avaliados, com média de $18 \mathrm{mg} .100 \mathrm{~mL}^{-1}$ A.A. Provavelmente, a maior acidez dos vinhos provenientes dos colmos armazenados contribuiu com a maior produção de acetato de etila ao final do $5^{\circ}$ ciclo, refletindo baixos níveis de acidez volátil no destilado.

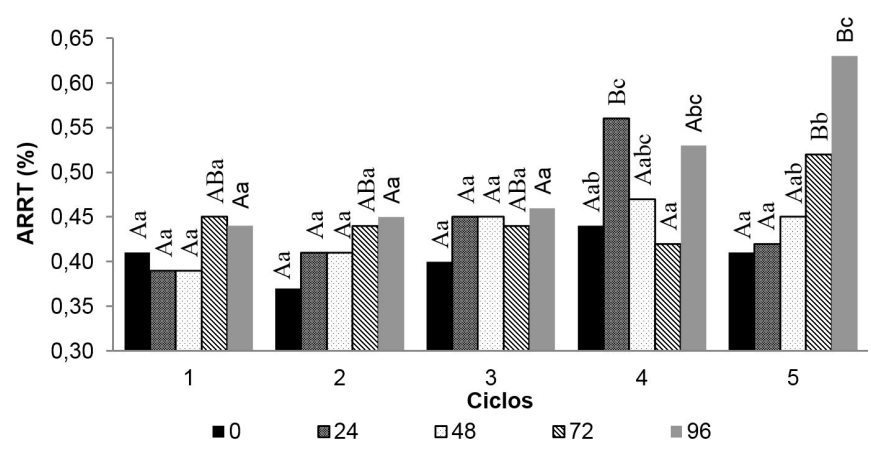

Figura 4. Interação entre tratamentos e ciclos para açúcares redutores residuais em mosto fermentado de cana colhida e armazenada. Letras maiúsculas comparam médias entre ciclos com mesmo tratamento. Letras minúsculas comparam médias entre os tratamentos de cada ciclo.

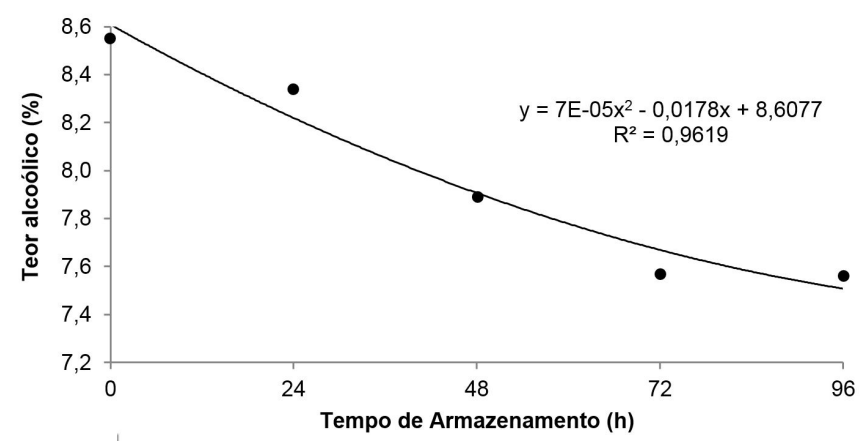

Figura 5. Valores médios de álcool em mosto fermentado de cana colhida e armazenada.
Comportamento semelhante foi descrito por Dato et al. (2005), ao observar maior produção de acetato de etila por S.cerevisiae, quando o $\mathrm{pH}$ dos vinhos foi reduzido.

O conteúdo de aldeídos da fração coração dos destilados foi inferior ao limite de $30 \mathrm{mg} .100 \mathrm{~mL}^{-1}$ A.A., estabelecido pela Legislação Brasileira. Verificou-se também uma variação na produção deste composto, com maiores níveis no $1^{\circ}$ ciclo para cachaças produzidas com colmos armazenados e ao final do $5^{\circ}$ ciclo para destilado de cana colhida e não armazenada.

Resultados semelhantes foram encontrados por Dato et al. (2005), que observaram maiores conteúdos de acetaldeído em cachaças produzidas por leveduras não Saccharomyces no primeiro ciclo fermentativo, enquanto ao final de dez ciclos a produção deste composto foi superior para fermentações conduzidas com Saccharomyces cerevisiae.

Observou-se ainda elevadas concentrações de álcoois superiores (álcool propílico, isobutílico e isoamílico) em todas as amostras de cachaça, com valores médios de 560,6 e 460,4 mg.100 $\mathrm{mL}^{-1}$ A.A., no $1^{\circ}$ e $5^{\circ}$ ciclos, respectivamente. Independentemente do armazenamento dos colmos de cana, o conteúdo destes álcoois foi superior ao estabelecido pela Legislação. A produção destes compostos é dependente da linhagem da levedura, sendo a síntese de álcoois superiores uma característica individual de cada espécie (ALCARDE et al., 2012a). Provavelmente, a produção elevada de álcoois superiores é uma característica intrínseca destas leveduras e, provavelmente, a redução destes álcoois ao final do $5^{\circ}$ ciclo ocorreu devido à introdução de novas linhagens de leveduras durante a condução dos ciclos fermentativos.

Os níveis de furfural observados foram superiores ao estabelecido pela Legislação em todos os destilados produzidos no $5^{\circ}$ ciclo. Quanto mais elevada a concentração de açúcares residuais no vinho, maior a produção de furfural e hidroximetilfurfural, através dos processos de desidratação de hexoses e pentoses (MAIA, 1994). Observou-se nesta pesquisa que a produção de furfural foi proporcional ao aumento de açúcares residuais presentes nos vinhos durante os ciclos, evidenciando que o comprometimento das leveduras no processo contribui com a formação deste composto durante a destilação.

Os compostos secundários totais foram maiores no $1^{\circ}$ ciclo (média de 613,5 mg. $100 \mathrm{~mL}^{-1}$ A.A.) para cachaças produzidas com colmos de cana armazenados, devido à maior produção de álcoois superiores e acetaldeído. Ao final do $5^{\circ}$ ciclo fermentativo, a concentração média de congêneres foi de 523,5 mg. $100 \mathrm{~mL}^{-1}$ A.A., devido ao menor recolhimento de álcoois superiores nas destilações.

Os níveis de metanol foram inferiores a $20 \mathrm{mg} .100 \mathrm{~mL}^{-1}$ A.A. (BRASIL, 2005a) para todos os destilados, demonstrando que as boas práticas durante 
Qualidade pós-colheita de colmos de cana armazenados e seus reflexos na produção de cachaça

Oliveira Filho, J. H. et al.

Tabela 3. Compostos secundários e contaminantes da fração "coração" de destilados produzidos com caldo de cana colhida e armazenada.

\begin{tabular}{|c|c|c|c|c|c|c|c|c|c|c|c|c|c|c|c|}
\hline & \multicolumn{15}{|c|}{ Armazenamento (h) / Ciclos fermentativos } \\
\hline & \multicolumn{3}{|c|}{0} & \multicolumn{3}{|c|}{24} & \multicolumn{3}{|c|}{48} & \multicolumn{3}{|c|}{72} & \multicolumn{3}{|c|}{96} \\
\hline & 1 & 3 & 5 & 1 & 3 & 5 & 1 & 3 & 5 & 1 & 3 & 5 & 1 & 3 & 5 \\
\hline $\begin{array}{c}\text { Acidez volátil } \\
\text { (mg.100 mL } \mathrm{mL}^{-1} \text { A.A.) }\end{array}$ & 20,96 & 17,81 & 17,49 & 19,29 & 18,56 & 17,65 & 17,95 & 16,35 & 21,32 & 17,95 & 17,10 & 18,65 & 18,21 & 17,11 & 18,40 \\
\hline $\begin{array}{c}\text { Aldeídos } \\
\text { (mg.100 } \mathrm{mL}^{-1} \text { A.A.) }\end{array}$ & 9,08 & 12,42 & 21,56 & 15,59 & 7,32 & 17,02 & 16,52 & 16,75 & 12,78 & 14,34 & 12,67 & 9,95 & 15,86 & 11,61 & 16,50 \\
\hline $\begin{array}{c}\text { Ésteres } \\
\text { (mg.100 } \mathrm{mL}^{-1} \text { A.A.) }\end{array}$ & 11,24 & 16,03 & 22,83 & 19,05 & 16,98 & 22,67 & 20,75 & 21,82 & 22,84 & 15,35 & 16,28 & 43,50 & 17,08 & 23,54 & 34,18 \\
\hline $\begin{array}{c}\text { Furfural } \\
\text { (mg.100 } \mathrm{mL}^{-1} \text { A.A.) }\end{array}$ & 3,61 & 3,05 & 5,78 & 2,98 & 5,95 & 6,77 & 2,91 & 3,81 & 8,73 & 2,77 & 5,49 & 7,21 & 2,81 & 6,49 & 6,75 \\
\hline $\begin{array}{c}\text { Álcool propílico } \\
\text { (mg.100 mL-1 A.A.) }\end{array}$ & 23,99 & 26,49 & 24,86 & 25,69 & 27,20 & 23,43 & 32,73 & 38,23 & 39,27 & 25,03 & 27,53 & 29,84 & 26,69 & 32,01 & 29,43 \\
\hline $\begin{array}{l}\text { Álcool isobutílico } \\
\text { (mg.100 mL } \mathrm{mL}^{-1} \text { A.A.) }\end{array}$ & 93,60 & 94,64 & 69,36 & 107,71 & 93,72 & 57,44 & 105,19 & 109,11 & 90,55 & 96,84 & 93,06 & 78,70 & 107,85 & 93,57 & 84,13 \\
\hline $\begin{array}{l}\text { Álcool isoamílico } \\
\text { (mg.100 mL-1 A.A.) }\end{array}$ & 413,53 & 416,17 & 360,19 & 455,11 & 418,59 & 307,83 & 435,11 & 440,43 & 337,00 & 429,46 & 403,90 & 350,39 & 423,83 & 369,00 & 382,40 \\
\hline $\begin{array}{l}\text { Álcoois superiores } \\
\text { (mg.100 mL } \mathrm{mL}^{-1} \text { A.A.) }\end{array}$ & 531,12 & 537,30 & 454,40 & 588,51 & 539,51 & 388,69 & 573,72 & 587,76 & 466,82 & 551,33 & 524,50 & 458,92 & 558,38 & 494,59 & 496,00 \\
\hline $\begin{array}{c}\text { Congêneres } \\
\text { (mg.100 } \mathrm{mL}^{-1} \text { A.A.) }\end{array}$ & 576,01 & 586,61 & 522,07 & 645,42 & 588,31 & 452,81 & 631,85 & 646,49 & 532,49 & 601,74 & 576,00 & 538,22 & 612,33 & 553,35 & 571,80 \\
\hline $\begin{array}{c}\text { Metanol } \\
\text { (mg.100 } \mathrm{mL}^{-1} \text { A.A.) }\end{array}$ & 6,70 & 4,60 & 3,22 & 4,64 & 4,15 & 3,33 & 4,74 & 5,50 & 4,45 & 4,52 & 3,96 & 3,86 & 3,85 & 3,41 & 3,22 \\
\hline $\begin{array}{l}\text { Cobre } \\
\left(m g \cdot L^{-1}\right)\end{array}$ & 3,58 & 2,16 & 2,34 & 2,52 & 2,57 & 2,07 & 3,62 & 3,37 & 3,60 & 2,02 & 1,85 & 2,27 & 2,75 & 2,79 & 2,28 \\
\hline $\begin{array}{c}\text { Carbamato de etila } \\
\qquad\left(\mu \mathrm{g} \cdot \mathrm{L}^{-1}\right)\end{array}$ & 167,73 & 157,45 & 95,76 & 150,68 & 140,40 & 87,82 & 135,72 & 133,57 & 143,16 & 137,32 & 150,14 & 147,11 & 144,14 & 147,22 & 117,64 \\
\hline
\end{tabular}

a extração do caldo e preparo do mosto contribuíram com a redução deste composto na cachaça.

Os teores de cobre nos destilados apresentaram-se dentro do limite estabelecido pela Legislação Brasileira, não excedendo a concentração de 5 mg. L $^{-1}$ (BRASIL, 2005a), independentemente da utilização de colmos de cana armazenados nas fermentações do mosto. A higienização adequada do aparelho de destilação permitiu reduzir a formação de azinhavre nas superfícies, mantendo assim baixas concentrações de cobre no destilado.

O conteúdo de carbamato de etila foi reduzido ao longo dos ciclos, exceto para destilados produzidos com colmos armazenados por períodos superiores a 48 horas, entretanto, sua concentração foi inferior a $210 \mathrm{mg} . \mathrm{L}^{-1} \mathrm{~A} . \mathrm{A}$. (BRASIL, 2005a, 2014). Acredita-se que o maior número de células inativadas nestes tratamentos tenha favorecido a produção de precursores nitrogenados nos vinhos através de aminoácidos provenientes das células hidrolisadas, intensificando assim a formação de carbamato de etila. Ough et al. (1988) encontraram aumentos deste composto, proporcionais ao conteúdo de arginina e precursores nitrogenados (ornitina, ácido glutâmico + asparagina e ureia) em vinhos.

\section{Conclusão}

O armazenamento dos colmos de cana por períodos superiores a 48 horas afetou negativamente a qualidade da matéria-prima, comprometendo o desempenho dos processos fermentativos, através da redução da viabilidade de células e brotos de leveduras ao longo dos ciclos e elevação na concentração de contaminantes no fermento reciclado.

Verificou-se também a importância da não utilização de colmos de cana armazenados por períodos superiores a 48 horas, visando à condução adequada do processo e à manutenção dos níveis de acetato de etila, furfural e carbamato de etila da cachaça dentro dos padrões estabelecidos pela Legislação.

\section{Referências}

AlCARDE, A. R.; MONTEIRO, B. M. S.; BELluCO, A. E. S. Composição química de aguardente de cana-de-açúcar fermentadas 
Qualidade pós-colheita de colmos de cana armazenados e seus reflexos na produção de cachaça

Oliveira Filho, J. H. et al.

por diferentes cepas de levedura Saccharomyces cerevisiae. Química Nova, São Paulo, v. 35, n. 8, p. 1612-1618, 2012a

ALCARDE, A.R.; SOUZA, L.M.; BORTOLETTO, A.M. Ethyl carbamate kinetics in double distillation of sugar cane spirit. Part 2: influence of type of pot still. Institute of Brewing \& Distilling, London, v. 118, n. 4, p. 352-355, 2012b.

AMORIM, H. V. Fermentação alcoólica, ciência \& tecnologia. Piracicaba: Fermentec, 2005. 448 p

BADOTTI, F.; BELLOCH, C.; ROSA, C. A.; BARRIO, E.; QUEROL, A. Physiological and molecular characterization of Saccharomyces cerevisiae cachaça strains isolated from diferente geographic regions in Brazil. World Journal of Microbiology and Biotechnology, New York, v. 26, n. 4, p. 579-587, 2010. http://dx.doi.org/10.1007/s11274-009-0206-0.

BANZATTO, D. A.; KRONKA, S. N. Experimentação agrícola. 4. ed. Jaboticabal: FUNEP, 2006. 237 p.

BHATIA, S. J.; UPPAL, S. K.; THIND, K. S.; BATTA, S. K. Post harvest quality deterioration in sugarcane under different environmental conditions. Sugar Tech, Indian, v. 11, n. 2, p. 154-160, 2009.

BORTOLETTO, A. M.; ALCARDE, A. R. Congeners in sugar cane spirits aged in casks of different woods. Food Chemistry, Barking, v. 139, n. 1-4, p. 695-701, 2013. http://dx.doi.org/10.1016/j. foodchem.2012.12.053. PMid:23561163.

BRASIL. Ministério da Agricultura, Pecuária e Abastecimento. Instrução Normativa $n^{\circ} 13$, de 29 de junho de 2005. Aprova o regulamento técnico para fixação dos padrões de identidade e qualidade para aguardente de cana e para cachaça. Diário Oficial [da] República Federativa do Brasil, Brasília, DF, 29 jun. 2005a. Disponível em: <http://www.agricultura.gov.br>. Acesso em: 03 set. 2013.

BRASIL. Ministério da Agricultura, Pecuária e Abastecimento. Instrução Normativa n ${ }^{\circ} 24$ de 08 de setembro de 2005. Aprova o manual operacional de bebidas e vinagres. Diário Oficial [da] República Federativa do Brasil, Brasília, DF, 08 set. 2005b. Disponível em: <http://www.agricultura.gov.br>. Acesso em: 19 out. 2013.

BRASIL. Ministério da Agricultura, Pecuária e Abastecimento. Instrução Normativa $n^{\circ} 28$, de 08 de agosto de 2014. Altera o subitem 5.1.2. do anexo da instrução normativa $n^{\circ} 13$, de 29 de junho de 2005. Diário Oficial [da] República Federativa do Brasil, Brasília, DF, 08 ago. 2014. Disponível em: <http://www. agricultura.gov.br>. Acesso em: 04 set. 2014.

CECCATO-ANTONINI, S. R. Microbiologia da fermentação alcoólica: a importância do monitoramento microbiológico em destilarias. São Carlos: EdUFSCar, 2010. 105 p.

CLEGG, B. S.; FRANK, R. Detection and quantitation of trace levels of ethyl carbamate in alcoholic beverages by selected ion monitoring. Journal Agricultural Food Chemistry, Washington, v. 36, n. 3, p. 502-505, 1988.
CONSECANA. Manual de instruções. 3. ed. Piracicaba, 2006, 112 p. Disponível em: <http://www.orplana.com.br/novosite/ manual_consecana.pdf >Acesso em: 15 jul. 2014.

COPERSUCAR. Manual de controle químico da fabricação de açúcar. Piracicaba, 2001. 1 CD-ROM.

DATO, M. C. F.; PIZAURO, J. M.; MUTTON, M. J. R. Analysis of the secondary compounds produced by Saccharomyces cerevisiae and wild yeast strains during the production of "cachaça". Brazilian Journal of Microbiology, São Paulo, v. 36, n. 1, p. 70-74, 2005.

DUARTE, W. F.; AMORIM, J. C.; SCHWAN, R. F. The effects of co-culturing non-saccharomyces yeast with $\mathrm{S}$. cerevisiae on the sugar cane spirit (cachaça) fermentation process. Antonie van Leeuwenhoek, Amsterdam, v. 103, n. 1, p. 175-194, 2013. http://dx.doi.org/10.1007/s10482-012-9798-8. PMid:22911390.

GARCIA, D. B.; RAVANELI, G. C.; MADALENO, L. L.; MUTTON, M. A.; MUTTON, M. J. R. Damages of spittlebug on sugarcane quality and fermentation process. Scientia Agricola, Piracicaba, v. 67, n. 5, p. 555-561, 2010. http://dx.doi.org/10.1590/S010390162010000500009.

GOMES, F. C. O.; SILVA, C. L. C.; VIANNA, C. R.; LACERDA, I. C. A.; BORELLI, B. M.; NUNES, A. C.; FRANCO, G. R.; MOURÃO, M. M.; ROSA, C. A. Identification of lactic acid bacteria associated with traditional cachaça fermentations. Brazilian Journal of Microbiology, São Paulo, v. 41, n. 2, p. 486-492, 2010. http:// dx.doi.org/10.1590/S1517-83822010000200031. PMid:24031520.

GUERRA, J. B.; ARAÚJO, R. A. C.; PATARO, C.; FRANCO, G. R.; MOREIRA, E. S. A.; MENDONÇA-HAGLER, L. C.; ROSA, C. A. Genetic diversity of Saccharomyces cerevisiae strains during the $24 \mathrm{~h}$ fermentative cycle for the production of the artesanal Brazilian cachaça. Letters in Applied Microbiology, Oxford, v. 33, n. 2, p. 106-111, 2001. http://dx.doi.org/10.1046/j.1472765x.2001.00959.x. PMid:11472516.

LANE, J. H.; EYNON, L. Determination of reducing sugars by Fehling solution with methylene blue indicator. London: Normam Roger, 1934, 8 p.

MAIA, A. B. R. A. Componentes secundários da aguardente. STAB: Açúcar, Álcool e Subprodutos, Piracicaba, v. 12, n. 6 , p. 29-34, 1994.

MAO, L.; QUE, F.; WANG, G. Sugar metabolism and involvement of enzymes in sugarcane (Saccharum officinarum L.) stems during storage. Food Chemistry, Barking, v. 98, n. 2, p. 338-342, 2006. http://dx.doi.org/10.1016/j.foodchem.2005.05.076.

NARENDRANATH, N. V.; THOMAS, K. C.; INGLEDEW, W. M. Effects of acetic acid and lactic acid on the growth of Saccharomuces cerevisiae in a minimal medium. Journal of Industrial Microbiology and Biotechnology, Houndmills, v. 26, n. 3, p. 171-177, 2001. http://dx.doi.org/10.1038/sj.jim.7000090. PMid:11420658.

NOVA, M. X. V.; SCHULER, A. R. P.; BRASILEIRO, B. T. R. V.; MORAIS JUNIOR, M. A. Yeast species involved in artesanal 
Qualidade pós-colheita de colmos de cana armazenados e seus reflexos na produção de cachaça

Oliveira Filho, J. H. et al.

cachaça fermentation in three stills with diferente technological levels in Pernambuco, Brazil. Food Microbiology, London, v. 26, n. 5, p. 460-466, 2009. http://dx.doi.org/10.1016/j.fm.2009.02.005. PMid: 19465241

OUGH, C. S.; CROWELL, E. A.; MOONEY, L. A. Formation of ethyl carbamate precursors during grape juice (Chardonnay) fermentation. I. Addition of amino acids, urea, and ammonia: effects of fortification on intracellular and extracellular precursors. American Journal of Enology and Viticulture, California, v. 39, n. 3, p. 243-249, 1988.

RAVANELI, G. C.; GARCIA, D. D.; MADALENO, L. L.; MUTTON, M. A.; STUPIELLO, J. P.; MUTTON, M. J. R. Spittlebug impacts on sugarcane quality and etanol production. Pesquisa Agropecuária Brasileira, Brasília, v. 46, n. 2, p. 120-129, 2011. http://dx.doi. org/10.1590/S0100-204X2011000200002.

RECHE, R. V.; LEITE NETO, A. F.; SILVA, A. A.; GALINARO, C. A.; OSTI, R. Z.; FRANCO, D. W. Influence of type of distillation apparatus on chemical profiles of Brazilian cachaças. Journal Agricultural and Food Chemistry, Washington, v. 55, n. 16, p. 6603-6608, 2007.

SILVA, L. F. L. F.; BERNADINO, C. D.; RÉ, F. E.; FURTADO, C. $H$. F.; AMORIM, H. V. Métodos analíticos para o controle da produção de açúcar e álcool. 3. ed. Piracicaba: Fermentec, 2003. $126 \mathrm{p}$.

SKINNER, K. A.; LEATHERS, T. D. Bacterial contaminants of fuel ethanol production. Journal of Industrial Microbiology and Biotechnology, Houndmills, v. 31, n. 9, p. 401-408, 2004. http://dx.doi.org/10.1007/s10295-004-0159-0. PMid:15338420.

SOLOMON, S.; BANERJI, R.; SHRIVASTANA, A. K.; SINGH, P.; SINGH, I.; VERMA, M.; PRAJAPATI, C. P.; SAWNANI, A. Post-harvest deterioration of sugarcane and chemical methods to minimize sucrose losses. Sugar Tech, Indian, v. 8, n. 1, p. 74-78, 2006.

SUMAN, A.; SOLOMON, S.; YADAV, D. V.; SINGH, M. Post-harvest loss in sugarcane quality due to endophytic microrganisms. Sugar Tech, Indian, v. 2, n. 4, p. 21-25, 2000.

VERMA, A. K.; SINGH, S. B.; AGARWAL, A. K.; SOLOMON, S. Influence of postharvest storage temperature, time, and invertase enzyme activity on sucrose and weight loss in sugarcane. Postharvest Biology and Technology, Amsterdam, v. 73, p. 14-21, 2012. http://dx.doi.org/10.1016/j.postharvbio.2012.04.014. WATT, D. A.; CRAMER, M. D. Post-harvest biology of sugarcane. Sugar Tech, Indian, v. 11, n. 2, p. 142-145, 2009. 